\title{
Estudo da Degradação "In Vitro" de Blendas de Poli ( $\beta$-Hidroxibutirato) (PHB) / Poli(L-Ácido Latico) (PLLA) na Forma de Filmes
}

\author{
Mirela Vanin, Cesar C. Santana \\ Faculdade de Engenharia Química, UNICAMP \\ Íris L. Torriani \\ Laboratório Nacional de Luz Síncrotron e Instituto de Física GW, UNICAMP \\ Tomás Privelic \\ Laboratório Nacional de Luz Síncrotron \\ Eliana A. R. Duek \\ Faculdade de Engenharia Mecânica, UNICAMP
}

\begin{abstract}
Resumo: Neste trabalho foi realizado um estudo de avaliação da degradação "in vitro" da blenda biorreabsorvível poli( $\beta$ hidroxibutirato) (PHB) / poli(L-ácido lático) (PLLA). As blendas PHB/PLLA na forma de filmes, nas composições 0/100, 30/70, 50/50, 70/30 e 100/0 (\% em massa), foram obtidas pelo método de evaporação do solvente. Os filmes obtidos foram imersos em solução tampão fosfato salino, PBS, (pH 7,4) por 12 meses em banho termostatizado à $37^{\circ} \mathrm{C}$. As amostras foram caracterizadas por MDSC, TG, DMA, SEM, WAXS e SAXS, antes e após o processo de degradação. Os resultados mostraram que a blenda PHB/PLLA é imiscível em todas as composições estudadas, apresentando morfologia com separação de fases. Observou-se que o PLLA perdeu propriedades mecânicas de tração mais rapidamente que o PHB, durante o processo de degradação, tornando-se mais quebradiço. Verificou-se também aumento no grau de cristalinidade e na espessura do período longo das cadeias poliméricas nas blendas em função da degradação, sugerindo aumento da lamela cristalina.
\end{abstract}

Palavras-chave: Blendas, polímeros biorreabsorvíveis, biomateriais, poli( $\beta$-hidroxibutirato) (PHB), poli(L-ácido lático) (PLLA).

\section{In Vitro Study of Degradation of Poly( $\beta$-Hydroxybutyrate) (PHB) / Poly(L-Lactic Acid) (PLLA) Blends in the Form of Films}

Abstract: In this work, "in vitro" degradation of poly( $\beta$-hydroxybutyrate) (PHB) / poly(L-lactic acid) (PLLA) blends was evaluated. Films of PHB/PLLA blends, in the compositions 0/100, 30/70, 50/50, 70/30 and 100/0 (\% weight), were fabricated by casting. The films obtained were immersed in a phosphate buffer solution, PBS (pH 7.4) for 12 months. The samples were characterized by MDSC, TG, DMA, SEM, WAXS and SAXS, before and after the degradation process. The results showed that the PHB/PLLA blends are immiscible and present phase separation as indicated by microscopy. The PLLA loses mechanical properties faster than PHB, during the degradation process. It was observed that the blends increased their crystallinity degree and long period thickness as a function of degradation time.

Keywords: Blends, bioreabsorbable polymers, biomaterials, poly( $\beta$-hydroxybutyrate) (PHB) and poly(L-lactic acid) (PLLA).

\section{Introdução}

Ao longo das últimas décadas, implantes biorreabsorvíveis têm sido experimentados e utilizados em muitos procedimentos cirúrgicos, como por exemplo, fixação de fraturas, substituição óssea, reparo de cartilagem, entre outros. Dependendo dos componentes do polímero, esses materiais são modelados a fim de apresentar propriedades funcionais adequadas para cada utilização, sendo que as propriedades do polímero resultam da associação de fatores mecânicos, térmicos e viscoelásticos ${ }^{[1]}$.

O entendimento e o controle do processo de degradação destes polímeros, bem como o efeito de seus produtos de degradação no organismo vivo é de fundamental importância ${ }^{[2]}$.

A degradação destes materiais pode ocorrer por meio de várias reações: oxidação, redução, eliminação, isomerização, e outras, por ação de enzimas ou não. A biorreabsorção de

Autor para correspondência: Eliana A. R. Duek, Departamento de Engenharia de Materiais, Faculdade de Engenharia Mecânica, UNICAMP, Caixa Postal 6122, CEP: 13083-970, Campinas, SP.E-mail: eliduek@fem.unicamp.br 
polímeros é dividida em dois estágios: decomposição e absorção. Somente polímeros constituídos por ligações metabólicas ou seus análogos com ligações hidrolisáveis são biorreabsorvíveis ${ }^{[3]}$.

Atualmente, os poli( $\alpha$-hidroxiácidos $)$ que são poliésteres alifáticos derivados de ácido glicólico, D,L-e L-ácido láctico, $\beta$-hidroxibutirato e $\varepsilon$-caprolactana, são os polímeros que mais têm encontrado aplicações na área biomédica como polímeros biorreabsorvíveis para prótese e liberação controlada de fármacos ${ }^{[4-9]}$. A melhoria em algumas propriedades destes materiais, como permeabilidade, taxa de biodegradação, propriedades de tensão, têm sido alcançadas por copolimerização de poliésteres e poli(éter-éster)es ${ }^{[4,6]}$.

A hidrólise química de cadeias instáveis é o principal mecanismo na degradação polimérica ${ }^{[10]}$. O primeiro evento mensurável na degradação dos poli( $\alpha$-hidroxi ésteres) é a perda de resistência mecânica devido ao decréscimo da massa molar. As cadeias poliméricas são solúveis no fluido extracelular quando a massa molar está abaixo de 7000 daltons. Neste momento, o material possui resistência mecânica muito baixa e o polímero começa a fragmentar-se devido à tensão mecânica local ${ }^{[11]}$.

Para polímeros semicristalinos a degradação hidrolílica ocorre em duas fases. Na primeira fase, a água penetra na superfície do dispositivo, atacando preferencialmente as cadeias químicas da fase amorfa, convertendo longas cadeias poliméricas em cadeias menores, e finalmente em fragmentos solúveis. Devido a isso, ocorre inicialmente uma redução na massa molar da fase amorfa sem a perda das propriedades físicas. Em seguida, inicia-se a perda das propriedades físicas e a água começa a fragmentar o dispositivo. Na segunda fase, ocorre o ataque enzimático dos fragmentos. A metabolização aos fragmentos resulta em uma rápida perda de massa polimérica ${ }^{[10]}$.

A degradação de polímeros "in vivo" difere da degradação "in vitro", principalmente porque "in vivo" o implante está submetido aos esforços mecânicos. Alguns fatores que contribuem para a degradação, resultando em gás carbônico e água, representam importante papel tanto na degradação "in vitro" como na "in vivo". A taxa de degradação do polímero "in vitro" e "in vivo" depende não somente da composição química, mas também do tamanho, forma, e da superfície do implante. Estes são fatores que podem ser sistematicamente variados e avaliados nas situações de teste "in vitro". As propriedades específicas, tais como, massa molar inicial, distribuição de massa molar, grau de cristalinidade e taticidade podem ser controladas e avaliadas antes da implantação ou do teste de degradação em solução tampãa ${ }^{[6]}$.

As respostas do hospedeiro ao material implantado são fatores que influenciam na degradação, porém não podem ser controlados. Sendo que, estes fatores causam diferenças entre a degradação "in vitro" e "in vivo". Num implante ósseo, por exemplo, a capacidade de cicatrização de um implante individual e de tamponamento do hospedeiro são dois dos muitos fatores que influenciam os resultados da osteosíntese usando implantes biodegradáveis. Além disso, a biocompatibilidade do fixador da fratura implantado está relacionada ao tamanho do implante e ao sistema imunológico do hospedeiro. Estes mecanismos de defesa diferem em cada espécie e ainda em cada indivíduo de uma mesma espécie ${ }^{[6]}$.

Dentro do contexto apresentado, os polímeros biorreabsorvíveis PHB e PLLA representam bons candidatos para utilização como implantes temporários na área médica. Dentre as propriedades discutidas e tidas como importantes para tal utilização, verifica-se que o PHB possui propriedades mecânicas inferiores às do PLLA, porém o PHB mantém tais propriedades por mais tempo durante o processo de degradação, sugerindo que a blenda PHB/PLLA pode vir a apresentar melhores propriedades mecânicas do que o PLLA puro. Assim, o desenvolvimento de um novo biomaterial, a blenda PHB/PLLA, representa possibilidade de aplicação na área médica, contribuindo para o avanço da tecnologia de implantes temporários e melhorando a qualidade de vida de futuros pacientes.

Com base neste estudo bibliográfico, o presente trabalho buscou avaliar o processo de degradação "in vitro" das blendas PHB/PLLA em diferentes composições, através das técnicas de análise MDSC, TG, DMA, SEM, WAXS e SAXS; a fim de analisar seu comportamento durante o processo de degradação hidrolítica.

\section{Experimental}

\section{Materiais}

Os polímeros empregados na preparação da blenda poli $(\beta$ hidroxibutirato) (PHB)/ poli(L-ácido lático) (PLLA) nas composições 0/100, 30/70, 50/50, 70/30 e 100/0 foram: PHB da Aldrich e PLLA da PURAC, ambos de grau analítico. O solvente usado foi o hexafluorisopropanol (HFIP) da Aldrich, grau analítico.

A solução tampão fosfato salino, PBS, pH 7,4, utilizada, foi preparada a partir de reagentes de grau analítico obtidos da Merck e água milli-Q, deionizada.

\section{Métodos}

\section{Preparação das blendas PHB/PLLA}

As blendas foram preparadas empregando-se a técnica de solubilização seguida de evaporação do solvente, "casting". Os polímeros foram solubilizados em HFIP, em frasco fechado sob agitação magnética por 2 horas, obtendo-se uma solução polimérica a $7 \%(\mathrm{~m} / \mathrm{v})$. Após a solubilização dos polímeros no solvente, a solução polimérica foi vertida numa placa de vidro, que era colocada em uma cuba de vidro totalmente fechada para a lenta evaporação do solvente, por 48 horas. $\mathrm{O}$ filme obtido foi seco em estufa a vácuo à $60^{\circ} \mathrm{C}$ por 8 horas, e depois armazenado em embalagem plástica no dessecador por 3 semanas para estabilização do processo de cristalização das amostras.

\section{Ensaio de degradação "in vitro" e caracterização}

Para o ensaio de degradação "in vitro", os filmes foram colocados em tubos fechados, com $20 \mathrm{~mL}$ de solução tampão 
fosfato salino $\mathrm{pH} 7,4 \mathrm{em}$ um banho termostatizado à $37^{\circ} \mathrm{C}$. A solução PBS era trocada periodicamente, e amostras das blendas eram retiradas do banho a cada dois meses até um máximo de doze meses de ensaio de degradação. As amostras retiradas do banho eram lavadas com água milli-Q e com etanol $\mathrm{PA}$, e secas em estufa a vácuo à $60^{\circ} \mathrm{C}$ por 8 horas. As amostras degradadas e secas foram caracterizadas para acompanhar o processo de degradação, através das técnicas: calorimetria diferencial de varredura modulada (MDSC), termogravimetria (TG), análise dinâmico mecânica
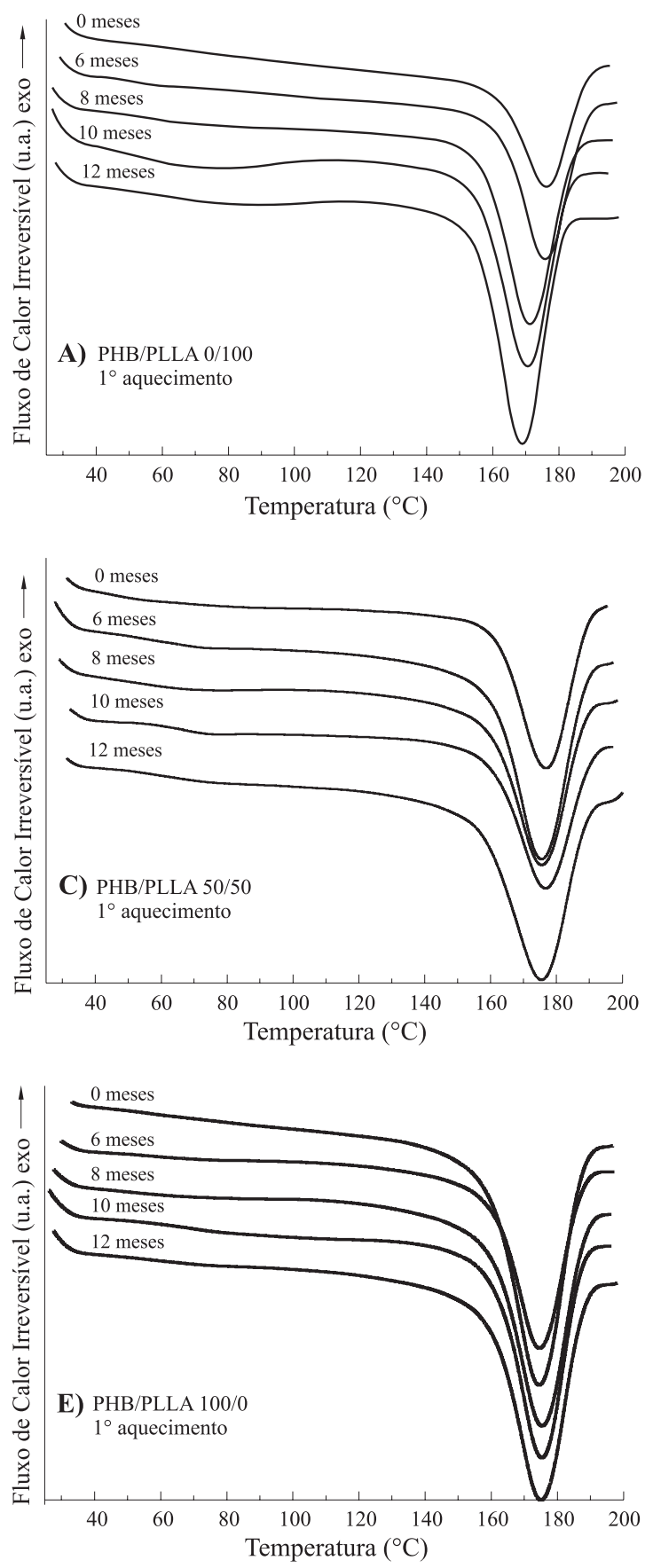

(DMA), microscopia eletrônica de varredura (SEM), difração de raios-X (WAXS) e espalhamento de raios-X a baixos ângulos (SAXS).

\section{Resultados e Discussão}

A Figura 1 mostra alguns termogramas de fluxo de calor irreversível do primeiro e segundo aquecimento. A Tabela 1 apresenta alguns dados de temperatura de transição vítrea (Tg), de cristalização (Tc), de fusão (Tm), entalpias de cristalização
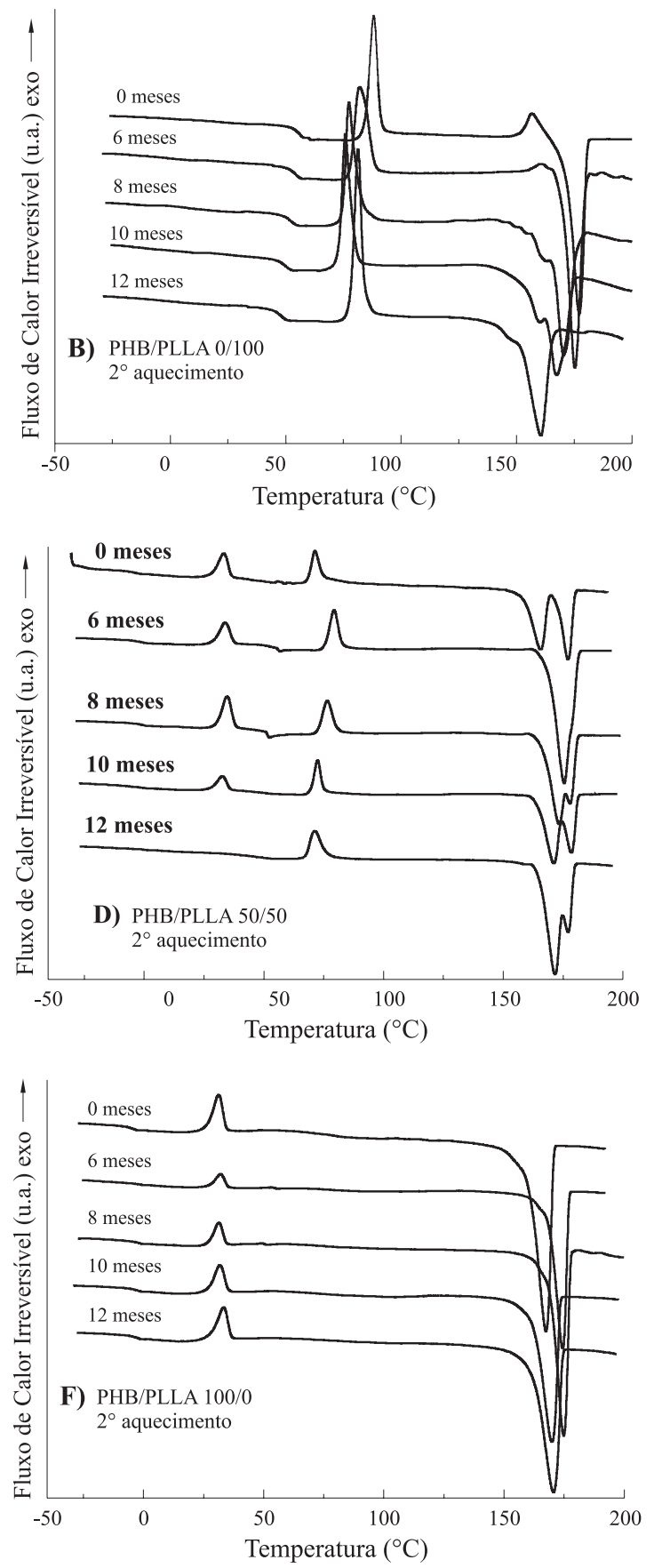

Figura 1. Curvas de MDSC obtidas para blendas de PHB/PLLA, em diferentes tempos de degradação: (A, C, E) $1^{\circ}$ aquecimento e (B, D, F) $2^{\circ}$ aquecimento. As análises foram feitas sob atmosfera de $\mathrm{N}_{2}$ e nas condições: $1^{\circ}$ aquecimento: de 25 a $210^{\circ} \mathrm{C}$ com rampa de $10^{\circ} \mathrm{C} /$ min. e modulação de $+/-0,5^{\circ} \mathrm{C} /$ min.; $2^{\circ}$ aquecimento: de -30 a $210{ }^{\circ} \mathrm{C}$ com rampa de $1{ }^{\circ} \mathrm{C} / \mathrm{min}$. e modulação de $+/-0,5^{\circ} \mathrm{C} / \mathrm{min}$. 
Tabela 1. Dados de temperatura de transição vítrea (Tg), de cristalização (Tc), de fusão (Tm), entalpias de cristalização $(\Delta \mathrm{Hc})$, de fusão $(\Delta \mathrm{Hf})$ e grau de cristalização $(\chi c)$, obtidos da análise de MDSC, para blendas de PHB/PLLA.

\begin{tabular}{|c|c|c|c|c|c|c|c|c|c|c|c|c|}
\hline \multicolumn{2}{|c|}{ Filmes } & \multicolumn{2}{|c|}{$\begin{array}{l}\text { Tg } \\
\left({ }^{\circ} \mathbf{C}\right)\end{array}$} & \multicolumn{2}{|c|}{$\begin{array}{c}\text { Tc } \\
\left({ }^{\circ} \mathbf{C}\right)\end{array}$} & \multicolumn{2}{|c|}{$\begin{array}{l}\Delta \mathbf{H c} \\
(\mathrm{J} / \mathrm{g})\end{array}$} & \multicolumn{2}{|c|}{$\begin{array}{l}\text { Tm } \\
\left({ }^{\circ} \mathbf{C}\right)\end{array}$} & \multirow{2}{*}{$\begin{array}{c}\begin{array}{c}\Delta \mathbf{H f} \\
(\mathbf{J} / \mathbf{g})\end{array} \\
\text { TOTAL }\end{array}$} & \multirow{2}{*}{$\begin{array}{c}\begin{array}{c}\chi c \\
(\%)\end{array} \\
\text { PLLA }\end{array}$} & \multirow{2}{*}{$\begin{array}{c}\begin{array}{l}\chi c \\
(\%)\end{array} \\
\text { PHB }\end{array}$} \\
\hline PHB/PLLA & Aquecimento & PHB & PLLA & PHB & PLLA & PHB & PLLA & PHB & PLLA & & & \\
\hline \multirow{2}{*}{$\begin{array}{c}0 / 100 \\
0 \text { meses }\end{array}$} & $1^{o}$ & - & - & - & - & - & - & - & 176 & 40 & 43 & - \\
\hline & $2^{\circ}$ & - & 56 & - & 88 & - & 25 & - & 177 & 44 & - & - \\
\hline \multirow{2}{*}{$\begin{array}{c}0 / 100 \\
12 \text { meses }\end{array}$} & $1^{o}$ & - & - & - & - & - & - & - & 169 & 84 & 90 & - \\
\hline & $2^{\circ}$ & - & 51 & - & 81 & - & 38 & - & 161 & 54 & - & - \\
\hline \multirow{2}{*}{$\begin{array}{c}50 / 50 \\
0 \text { meses }\end{array}$} & $1^{o}$ & - & - & - & - & - & - & \multicolumn{2}{|c|}{177} & 57 & 30 & 20 \\
\hline & $2^{\circ}$ & -1 & 51 & 33 & 71 & 10 & 13 & 165 & 177 & 58 & - & - \\
\hline \multirow{2}{*}{$\begin{array}{c}50 / 50 \\
12 \text { meses }\end{array}$} & $1^{\mathrm{o}}$ & - & - & - & - & - & - & \multicolumn{2}{|c|}{175} & 76 & 41 & 26 \\
\hline & $2^{\circ}$ & - & 53 & - & 71 & - & 13 & 172 & 177 & 71 & - & - \\
\hline \multirow{2}{*}{$\begin{array}{c}100 / 0 \\
0 \text { meses }\end{array}$} & $1^{\circ}$ & - & - & - & - & - & - & 175 & - & 89 & - & 61 \\
\hline & $2^{\circ}$ & -1 & - & 31 & - & 13 & - & 168 & - & 97 & - & - \\
\hline \multirow{2}{*}{$\begin{array}{c}100 / 0 \\
12 \text { meses }\end{array}$} & $1^{\circ}$ & - & - & - & - & - & - & 175 & - & 99 & - & 68 \\
\hline & $2^{\circ}$ & 1 & - & 34 & - & 15 & - & 171 & - & 100 & - & - \\
\hline
\end{tabular}

$(\Delta \mathrm{Hc})$, de fusão $(\Delta \mathrm{Hf})$ e grau de cristalização $(\chi c)$, da análise de MDSC.

Mesmo usando o DSC com temperatura modulada, não foi possível observar as Tg's no $1^{\circ}$ aquecimento, possivelmente porque o método de preparação das amostras, "casting" proporcionou maior cristalização das amostras. Tal afirmação se baseia em resultados diferentes destes, obtidos pelos autores num estudo paralelo com amostras preparadas por mistura física no estado fundido. Além disso, no caso das blendas, a presença do PHB que é altamente cristalino também contribuiu para tal processo. Assim, a porção amorfa ficou muito pequena dificultando a deteç̧ão da $\operatorname{Tg}$ no $1^{\circ}$ aquecimento, pelo equipamento.

Através dos resultados do $2^{\circ}$ aquecimento, verificou-se que as blendas são imiscíveis, apresentando duas Tg's. Ainda no $2^{\circ}$ aquecimento, o PLLA puro apresentou decréscimo na $\mathrm{Tg}$ em função da degradação, de 56 para $51^{\circ} \mathrm{C}$, conforme Tabela 1 . Para as blendas PHB/PLLA observou-se aumento nas Tg's devido à alta cristalinidade dificultando a mobilidade das cadeias amorfas. Enquanto que, o PHB não apresentou mudanças significativas nos valores da Tg. O PLLA puro $\left(2^{\circ}\right.$ aquecimento) apresentou decréscimo na Tc e aumento no $\Delta \mathrm{Hc}$ em função da degradação. $\mathrm{O}$ decréscimo na Tc pode ser atribuído à rápida relaxação de cadeias com menor massa molecular relacionada à degradação hidrolítica. Tais cadeias cristalizam-se mais facilmente necessitando de menores temperaturas de cristalização. $\mathrm{O}$ aumento do $\Delta \mathrm{Hc}$ e da cristalinidade, em função da degradação, verificados aqui, tem sido constatado e discutido por outros autores ${ }^{[2,7,12]}$. Neste estudo, acredita-se que houve um rearranjo de cadeias menores geradas pelo próprio processo de degradação com a conseqüênte formação de novos cristais. A Tm do PLLA puro decresce tanto no $1^{\circ}$ como no $2^{\circ}$ aquecimento, porque o processo de degradação, ou diminuição da massa molar, do PLLA promove a formação de novos cristais, de menor massa molar, os quais podem ser fundidos com menores energias e temperaturas. As Tm's para as blendas e para o PHB puro permanecem constantes. O $\Delta \mathrm{Hf}$ para todas as amostras aumenta em função da degradação, assim como o grau de cristalinidade.

A Figura 2 e Tabela 2 apresentam alguns resultados obtidos da termogravimetria (TG). As curvas de TG (Figura 2) mostram 


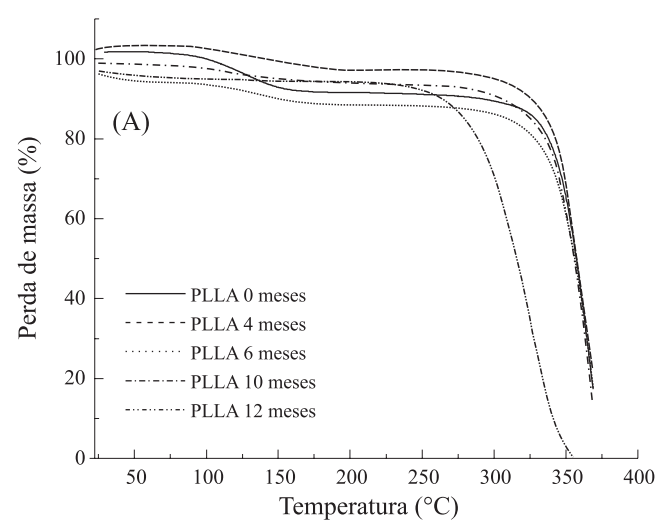

Tabela 2. Valores das temperaturas de início ( $T$ on set) e máxima velocidade ( $T$ peak) de perda de massa e $\%$ de perda de massa para blendas de PHB/PLLA, em diferentes tempos de degradação "in vitro".

\begin{tabular}{|c|c|c|c|c|c|c|}
\hline \multirow{2}{*}{$\begin{array}{c}\text { PHB/ } \\
\text { PLLA }\end{array}$} & \multicolumn{2}{|c|}{$\begin{array}{l}\mathbf{T}_{\text {onset }} \\
\left({ }^{\circ} \mathbf{C}\right)\end{array}$} & \multicolumn{2}{|c|}{$\begin{array}{l}\mathbf{T}_{\text {peak }} \\
\left({ }^{\circ} \mathbf{C}\right)\end{array}$} & \multicolumn{2}{|c|}{$\begin{array}{c}\text { Perda de massa } \\
(\%)\end{array}$} \\
\hline & PHB & PLLA & PHB & PLLA & PHB & PLLA \\
\hline $\begin{array}{c}0 \\
\text { meses }\end{array}$ & - & 346 & - & 365 & - & 86 \\
\hline 4 & - & 344 & - & 364 & - & 89 \\
\hline 6 & - & 344 & - & 365 & - & 85 \\
\hline 10 & - & 346 & - & 365 & - & 94 \\
\hline 12 & - & 295 & - & 329 & - & 97 \\
\hline $30 / 70$ & PHB & PLLA & PHB & PLLA & PHB & PLLA \\
\hline $\begin{array}{c}0 \\
\text { meses }\end{array}$ & 266 & 337 & 281 & 363 & 28 & 62 \\
\hline 4 & 266 & 338 & 280 & 360 & 30 & 64 \\
\hline 10 & 268 & 338 & 284 & 360 & 29 & 67 \\
\hline 12 & 270 & 338 & 282 & 360 & 32 & 62 \\
\hline $\mathbf{5 0 / 5 0}$ & PHB & PLLA & PHB & PLLA & PHB & PLLA \\
\hline $\begin{array}{c}0 \\
\text { meses }\end{array}$ & 368 & 332 & 280 & 352 & 49 & 47 \\
\hline 4 & 265 & 333 & 278 & 352 & 51 & 50 \\
\hline 10 & 270 & 334 & 281 & 258 & 52 & 46 \\
\hline 12 & 270 & 333 & 280 & 357 & 52 & 45 \\
\hline $70 / 30$ & PHB & PLLA & PHB & PLLA & PHB & PLLA \\
\hline $\begin{array}{c}0 \\
\text { meses }\end{array}$ & 268 & 324 & 276 & 344 & 63 & 29 \\
\hline 4 & 264 & 324 & 278 & 344 & 69 & 30 \\
\hline 10 & 266 & 326 & 280 & 347 & 70 & 27 \\
\hline 12 & 267 & 325 & 277 & 345 & 69 & 27 \\
\hline $100 / 0$ & PHB & PLLA & PHB & PLLA & PHB & PLLA \\
\hline $\begin{array}{c}0 \\
\text { meses }\end{array}$ & 264 & - & 277 & - & 97 & - \\
\hline 4 & 267 & - & 281 & - & 98 & - \\
\hline 6 & 266 & - & 277 & - & 90 & - \\
\hline 10 & 266 & - & 276 & - & 99 & - \\
\hline 12 & 265 & - & 278 & - & 100 & - \\
\hline
\end{tabular}

Figura 2. Curvas de perda de massa (\%) em função da temperatura da análise de TG para blendas de PHB/PLLA, em diferentes tempos de degradação. As análises foram realizadas sob atmosfera de $\mathrm{N}_{2}$, e com uma taxa de aquecimento de $10^{\circ} \mathrm{C} / \mathrm{min}$.

$\mathrm{T}_{\text {on set }}=$ temperatura de início de perda da massa

$\mathrm{T}_{\text {peak }}^{\text {on set }}=$ temperatura de máxima de perda de massa 
um único estágio de perda de massa para os homopolímeros e dois para as blendas, relativos à perda de massa do PHB e do PLLA, respectivamente, que também variam de acordo com a porcentagem em massa de cada componente da blenda.

Analisando os resultados apresentados na Figura 2 e na Tabela 2, verifica-se que o PLLA puro sofreu degradação parcial no período de 12 meses de ensaio, apresentando decréscimos de 51 e $36{ }^{\circ} \mathrm{C}$ para $\mathrm{T}_{\text {on set }}$ e $\mathrm{T}_{\text {peak }}$, respectivamente. $\mathrm{O}$ decréscimo nas temperaturas foi mais significativo após 10 meses de degradação. Esse fato também foi observado nas análises de MDSC, DMA e SEM. Ainda para o PLLA puro, verifica-se um acréscimo na porcentagem de perda de massa em torno de $11 \%$ durante a degradação. Para as misturas não se verifica variação significativa nos valores das temperaturas analisadas, $T_{\text {on set }} \mathrm{e}$ $\mathrm{T}_{\text {peak }}$ que permanecem constantes durante o período de degradação. O mesmo pode ser observado para o PHB puro.

Analisando a Tabela 3 relativa à análise de DMA, observa-se que os homopolímeros apresentam uma $\mathrm{Tg}$, enquanto as blendas apresentam duas, indicando imiscibilidade, concordante com o resultado de MDSC.

Pode-se observar também através da Tabela 3 que as Tg's aumentam em função da degradação, possivelmente devido ao aumento da cristalinidade das amostras durante tal processo. Além disso, pôde-se notar perda de propriedades mecânicas do PLLA puro e das blendas PHB/PLLA 30/70 e 50/50. Não foi possível fazer a análise de DMA para tais amostras após períodos de 6 e/ou 10 meses, já que as amostras ficaram quebradiças, devido à degradação.

As amostras apresentaram-se esbranquiçadas após um período de dois meses de ensaio de degradação hidrolítica. Analisando as amostras macroscopicamente, observou-se que os filmes degradaram, pois as amostras começaram a se quebrar, perdendo propriedades mecânicas como já discutido na análise de DMA, sobretudo o PLLA puro e as misturas 30/70 e 50/50. Ferreira $^{[12]}$ também observou na mistura PLLA/PHBV que o PLLA apresentou-se quebradiço com a degradação hidrolítica.

Tabela 3. Temperaturas de transição vítrea (Tg), das curvas de módulo de perda (E”) e damping $(\tan \delta$ ) para as blendas PHB/PLLA, obtidas por DMA.

\begin{tabular}{|c|c|c|c|c|c|}
\hline \multirow{2}{*}{$\begin{array}{l}\text { PHB/ } \\
\text { PLLA }\end{array}$} & \multirow{2}{*}{$\begin{array}{c}\text { Tempo de } \\
\text { degradação } \\
\text { (meses) }\end{array}$} & \multicolumn{2}{|c|}{$\operatorname{Tg}\left({ }^{\circ} \mathbf{C}\right)$ do $E^{\prime \prime}$} & \multicolumn{2}{|c|}{$\operatorname{Tg}\left({ }^{\circ} \mathrm{C}\right)$ da Tan $\delta$} \\
\hline & & PHB & PLLA & PHB & PLLA \\
\hline \multirow{3}{*}{$0 / 100$} & 0 & - & 47 & - & 67 \\
\hline & 4 & - & 45 & - & 54 \\
\hline & 6 & - & 49 & - & 72 \\
\hline \multirow{2}{*}{$50 / 50$} & 0 & 6 & 68 & 10 & 71 \\
\hline & 6 & 12 & 66 & 12 & 66 \\
\hline \multirow{3}{*}{$100 / 0$} & 0 & 6 & - & 13 & - \\
\hline & 6 & 13 & - & 20 & - \\
\hline & 12 & 17 & - & 23 & - \\
\hline
\end{tabular}
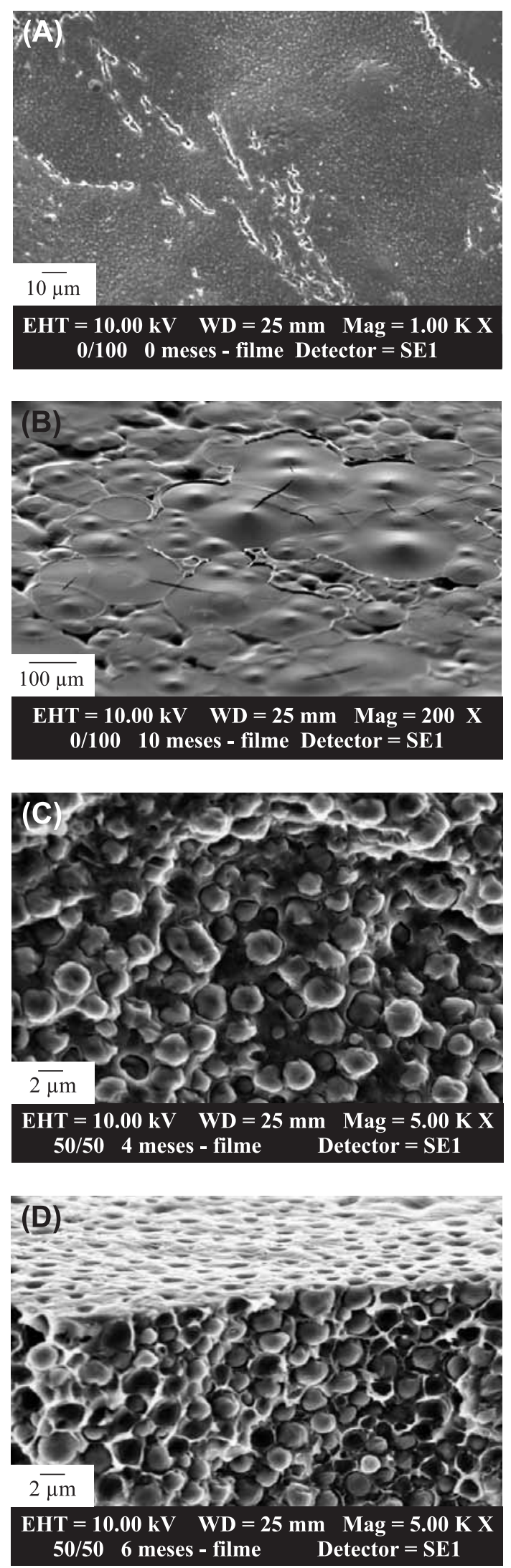

Figura 3. Micrografias da análise de SEM: (a) superfície PLLA puro (0 mês aumento 1000x); (b) superfície PLLA puro (10 meses aumento 200x); (c) superfície da fratura 50/50 (4 meses aumento de 5000x); (d) superfície da fratura 50/50 (6 meses aumento de 5000x). 
Tabela 4: Resultados das análises de WAXS (grau de cristalinidade) e SAXS (período longo) das blendas PHB/PLLA durante a degradação hidrolítica.

\begin{tabular}{|c|c|c|c|c|}
\hline \multirow{2}{*}{$\begin{array}{l}\text { PHB/ } \\
\text { PLLA }\end{array}$} & \multirow{2}{*}{$\begin{array}{c}\text { Tempo de } \\
\text { degradação } \\
\text { (meses) }\end{array}$} & \multicolumn{2}{|c|}{$\begin{array}{c}\text { Período longo } \\
\text { L (̊) }\end{array}$} & \multirow{2}{*}{$\begin{array}{c}\text { Grau de } \\
\text { Cristalinidade } \\
\chi(\%)\end{array}$} \\
\hline & & PHB & PLLA & \\
\hline \multirow{2}{*}{$0 / 100$} & 0 & - & 205 & 76 \\
\hline & 4 & - & $* 447$ & 82 \\
\hline \multirow{2}{*}{$50 / 50$} & 0 & 69 & 137 & 71 \\
\hline & 4 & 69 & $* 447$ & 84 \\
\hline \multirow{2}{*}{$100 / 0$} & 0 & 71 & - & 82 \\
\hline & 4 & 70 & - & 84 \\
\hline
\end{tabular}

Analisando a Figura 3, referente à análise de SEM, verifica-se que após 10 meses de ensaio de degradação, as amostras de PLLA puro apresentam trincas caracterizando a ocorrência de degradação durante tal período. Com relação às blendas, verificou-se que a blenda que apresentou maior evidência de degradação foi a 50/50, pois no tempo zero observou-se nítida separação de fases, e com a degradação foi possível verificar que uma das fases vai degradando. Com seis meses tem-se a amostra totalmente porosa e com 12 meses só se observa uma fase, como se a outra tivesse sido retirada, no caso degradada. Sugere-se que a fase que degradou foi a do PLLA, já que através das micrografias e das análises de MDSC e DMA, o PLLA apresenta maior variação em suas propriedades térmicas e mecânicas, caracterizando sua degradação. O PHB aparentemente não apresenta mudanças morfológicas que caracterizem um processo de degradação.

Resultados similares foram observados por Koyama ${ }^{[13]}$ que estudou a degradação hidrolítica da mistura $\mathrm{P}(\mathrm{R})-3-\mathrm{HB} / \mathrm{P}(\mathrm{R}$, S)LA, o autor concluiu que o $\mathrm{P}(\mathrm{R}, \mathrm{S}) \mathrm{LA}$ acelera o processo de cisão das cadeias de $\mathrm{P}(\mathrm{R})-3-\mathrm{HB}$, devido ao efeito catalítico dos oligômeros de $\mathrm{P}(\mathrm{R}, \mathrm{S}) \mathrm{LA}$ na matriz de $\mathrm{P}(\mathrm{R})-3-\mathrm{HB}$.

As análises de WAXS confirmaram o aumento do grau de cristalinidade em função da degradação que pode ser verificado através da Tabela 4 . A largura à meia altura dos picos característicos da cristalização diminuíram com a degradação; sabendo que, o tamanho dos cristalitos é inversamente proporcional à largura à meia altura dos picos de difração, pode-se sugerir que os cristalitos crescem em função da degradação.

Através das análises de SAXS pode-se obter valores de $\mathrm{q}^{*}$ (pico de interferência) e pela equação de Bragg $\left(\mathrm{d}_{1}=2 \pi / \mathrm{q}^{*}\right)$ consegue-se obter valores referentes ao período longo $\left(\mathrm{d}_{1}\right)$ que caracteriza $1_{\mathrm{C}}$ (lamela cristalina) $+\mathrm{l}_{\mathrm{a}}$ (lamela amorfa). $\mathrm{O}$ menor valor de $\mathrm{q}^{*}$ detectável pelo equipamento é de 0,015 $\AA^{-1}$. Portanto, pode-se inferir que o maior período longo observado pelo equipamento é de $447 \AA$.

As análises de SAXS mostraram que a espessura do período longo (espessura da camada amorfa + espessura da camada cristalina) das amostras cresce em função da degradação (vide Tabela 4). O pico de interferência característico do PLLA puro ou na blenda desaparece, provavelmente por estar num valor de $\mathrm{q}^{*}$ abaixo do limite detectável pelo equipamento. Assim, pode haver uma inter-relação entre aumento da espessura do período longo e crescimento dos cristalitos, sugerindo aumento da espessura da camada cristalina, concordando com o aumento da cristalinidade em função da degradação observado pelas análises de MDSC e DMA.

\section{Conclusões}

Através da caracterização das amostras degradadas concluiu-se que o PLLA degrada-se mais rapidamente que o PHB, e que durante a degradação têm-se um aumento da cristalinidade das amostras. Verificou-se que, apesar do PHB apresentar propriedades mecânicas inferiores às do PLLA, o PHB consegue mantê-las por mais tempo, enquanto que o PLLA apresenta-se quebradiço em poucos meses de ensaio. Podese sugerir então que as blendas apresentam vantagens em relação ao tempo de degradação e propriedades mecânicas quando comparadas ao PLLA puro.

\section{Agradecimentos}

Os autores agradecem à FAPESP (processo no. 98/12680-4) e à FINEP/Pronex pelo suporte financeiro; e ao Laboratório Nacional Luz Síncrontron (LNLS), pelas análises de WAXS e SAXS.

\section{Referências Bibliográficas}

1. Yuehuei, H. A.; Shane K. W.; Richard, J. F. - Biomaterials, 21, p.2635 (2000).

2. Ferreira, B. M. P.; Zavaglia, C. A. C.; Duek, E. A. R. - Materials Research, 4, p.34 (2001).

3. Kimura, Y. - "Biodegradable Polymers", in: Biomedical Applications of Polymeric Materials. p. 163-189, CRC Press (ed.), EUA (1993).

4. Zhang, L.; Xiong, C.; Deng, X. - J Appl Polym Sci, 56, p.103 (1995).

5. Ignatius, A. A.; Claes, L. E. - Biomaterials, 17, p.831 (1996).

6. Elst, M. V. - J Biomed Mater Res, 30, p.139 (1996).

7. Duek, E. A. R.; Zavaglia, C. A. C.; Belangero, W. D. - Polymer, 40, p.6465 (1999).

8. Reis, R. L.; Cunha, A. M. - J. Mat. Sci.: Materials in Medicine, 6, p.786 (1995).

9. Park, S. H.; Lim, S. T.; Shin, T. K.; Choi, H. J.; Jhon, M. S. Polymer, 42, p.5737 (2001).

10. Middleton, J. C.; Tripton, A. J. - Biomaterials, 21, p.2335 (2000).

11. Wake, M.C.; Gerecht, P. D.; Lu, L.; Mikos, A. G. - Biomaterials, 19, p.1255 (1998).

12. Ferreira, B. M. P. - “Obtenção, Caracterização, Estudo "In Vitro"e "In Vivo"de Blendas de Poli(L-ácido láctico)/ Poli(hidroxibutirato-co-hidroxivalerato)", Tese de Doutorado, Universidade Estadual de Campinas, Brasil (2002).

13. Koyama, N.; Dói, Y. - Can J Microbiol, 41, p.316 (1995).

Enviado: $15 / 12 / 03$

Reenviado: 03/06/04 Aprovado: 08/06/04 